\title{
The Effect of Neural Therapy on Long-Term Postoperative Discomforts after Bilateral Tubal Ligation
}

\author{
Pınar Yalçın Bahat ${ }^{a}$ Bahar Yüksel Özgör ${ }^{b}$ Gökçe Turan ${ }^{a}$ \\ Nura Fitnat Topbaş Selçuki ${ }^{a}$ Hüseyin Nazlıkulc \\ alHealth Sciences University, İstanbul Kanuni Sultan Suleyman Training and Research Hospital, Department of \\ Obstetrics and Gynecology, Istanbul, Turkey; ${ }^{\text {b}}$ Esenler Maternity and Research Hospital, Department of Obstetrics

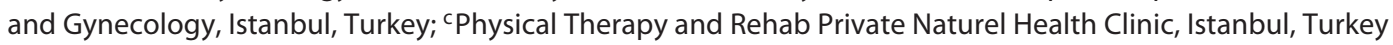

\section{Retraction Statement see next page}




\section{Retraction Statement}

Paper by Yalçın Bahat et al., entitled "The Effect of Neural Therapy on Long-Term Postoperative Discomforts after Bilateral Tubal Ligation" [Complement Med Res. 2020;1-5, DOI: 10.1159/000507108]

After publication of the article entitled "The Effect of Neural Therapy on Long-Term Postoperative Discomforts after Bilateral Tubal Ligation" [Complement Med Res. 2020;1-5, DOI: 10.1159/000507108] by P. Yalçın Bahat, B. Yüksel Özgör, G. Turan, N.F. Topbaş Selçuki, and H. Nazlıkul, concerns were raised about several aspects of the methods and statistical analyses. As a result, the authors wish to retract the paper and apologize for any inconvenience caused.

Harald Walach, Editor-in-Chief 